\title{
Every physician a psychoanalyst? Implications of the Adverse Childhood Experiences study
}

I walked into the intermediate care unit for the first time, a second-year student entering a ward filled with patients suffering from severe disease and debilitation. Most suffered from a panoply of illnesses obscuring any single impending cause of death. Many were dying from diseases with widely recognized risk factors: patients who smoked heavily now ventilator dependent, a morbidly obese patient dying of heart failure, a patient with alcoholism suffering with liver damage. It seemed I was walking in at the end of a story.

The Adverse Childhood Experiences (ACE) study offers a beginning by providing an understanding of why some people cannot effectively care for themselves. The Centers for Disease Control, collaborating with the Health Appraisal Clinic in San Diego, studies the life-long health effects of early childhood abuse on 17000 patients. This cohort was drawn from members of the San Diego branch of the US Health Insurer Kaiser Permanente; the cohort was neither impoverished nor uneducated and matched social norms in education and income. ${ }^{1}$ Participants in the study completed a questionnaire covering three categories: major physical, sexual or psychological abuse, severe neglect, and major household dysfunction. Each participant was given an ACE score from 1 to 7 . These early experiences, when measured and quantified as an ACE score, have a strong doseresponse correlation with illnesses that are both devastating and common later in life, many one would not have thought of as arising from childhood trauma.

The ACES study has changed my practice. I started screening patients. (SW)

"Sometimes, people with chronic abdominal pain have had a history of abuse; it can be physical, psychological or sexual."

"Yes."
"Which type?"
"All of them."

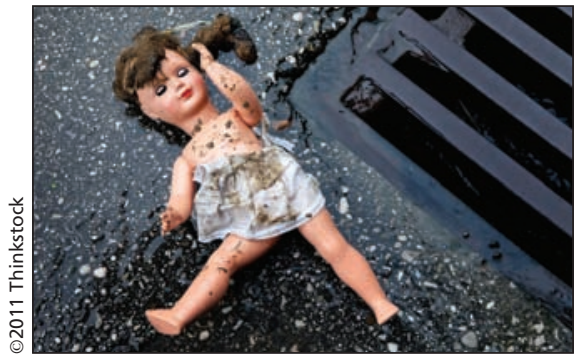

"Do you want to talk about it?"

"My father was an alcoholic; he used to beat my mother. I tried to stop him, but I couldn't. One time he broke her arm."

A high ACE score is associated with a greater risk of tobacco, alcohol and drug use, of overeating and of high-risk sexual behaviour. The study's head researcher postulates that this may be related to "self-treatment of concealed problems that occurred in childhood." This self treatment has enormous human and financial costs. Increased ACEs mean increased rates of ischemic heart disease, of liver disease, of chronic obstructive pulmonary disease (COPD), lung cancer and sexually transmitted infections. It means more teen pregnancy and fetal death, more depression and hallucinations, more suicidal thoughts and behaviours, and more prescription drug use. ${ }^{2}$ And it's not just risk factors leading to disease: chronic stress is toxic, which perhaps explains why a traumatic childhood means, for example, more autoimmune disease, and that the higher rates of COPD that are only partially reduced by correcting for smoking.

"Your weight is a serious problem for your health. Sometimes people who have trouble eating have had difficult childhoods. Can you tell me about yours?"

"When I was five I was in a boarding school. I was woken up early two hours before breakfast. I used to pass out, almost every morning from hunger, I guess. I tried but I just couldn't stop it. Finally, after a year they let me skip morning services."

It seems astounding that such a long list of adverse outcomes could arise from childhood traumas. Perhaps more surprising is that, if this study population represents the population of North America as a whole, traumatic childhood experiences are also far more common than most people think. More than half of the ACE study participants had at least one ACE score ${ }^{1}$ and of course many other sources of uncounted trauma could exist. On a societal level, the results strongly suggest that to effectively tackle preventable illness, we intervene when tomorrow's patients are today's children.

"I smoke for my nerves. No my childhood was fine. We had enough money; my father had a steady job. We weren't worse off than anyone else. My problems have nothing to do with that, it's just the way I am."

The recognition that people are made, not born, to suffer should be in the back of the mind of every physician and medical student.

"I once asked a suicidal patient why she was suicidal. After she told me about her life and childhood, I thought I'd probably be suicidal too."

\section{Keith Baglole BA}

Medical student, class of 2013

Stephen Workman MD

General Internal Medicine

Dalhousie University

Halifax, NS

The author confirms that the patients mentioned here are fictitious.

\section{References}

1. Adverse Childhood Experiences (ACE) Study. Atlanta (GA): Center for Disease Control and Prevention; 2011. Available: www.cdc.gov/ace/index .htm (accessed 2011 May 23).

2. Felitti VJ. The relationship of adverse childhood events to adult health: turning gold into lead [article in German]. Z Psychsom Med Psychother 2002;48: 359-69.

3. Felitti VJ, Anda RF. The relationship of adverse childhood experiences to adult health status. San Diego (CA): Kaiser Permanente and Atlanta (GA): The Centers for Disease Control. Available: www .gfmer.ch/PGC_RH_2005/pdf/ACE.pdf (accessed 2011 June 14). 